\title{
ESTRUTURAS DE DIFERENÇA NO PALIN, ESPORTE MAPUCHE*
}

Magnus Course

\begin{abstract}
Não deixem que se extinga aquilo que sabemos sobre o jogo; foi nosso conhecimento a respeito que nos tornou o povo invencível (Fermin Trekamañ, Cacique de Pelal, 1911 apud Manquilef 1914:20).
\end{abstract}

Em 1674, em sua Historia general del reino de Chile (1989 [1674]), o padre jesuíta Diego de Rosales publicou uma descrição detalhada do palin, esporte mapuche. Lendo uma cópia desta obra, fiquei um tanto surpreso ao descobrir que o palin, tal como descrito por Rosales, era praticamente idêntico aos vários jogos que observei quase 350 anos depois, durante meu trabalho de campo nas comunidades mapuche junto ao lago Budi, no Chile meridional. Nestas comunidades, o palin é fonte permanente de discussão, rememoração e inspiração - tanto para os velhos quanto para os jovens.

Neste artigo, procuro elucidar a razão pela qual, a despeito de mudanças radicais no próprio tecido da sociedade, o palin continua a ter importância significativa na imaginação dos Mapuche. Minha resposta se dará com a sugestão de que o palin é melhor entendido como uma instituição composta de uma forma particular de relação: a oposição assimétrica. Neste tipo de relação, ao invés de compreender os elementos como categorias fixas em oposição equilibrada, seguirei etnógrafos de outras sociedades ameríndias, como Lévi-Strauss $(1963,1996)$ e Viveiros de Castro $(1992,1998,2001)$, que consideram tais oposições como relações intrinsecamente dinâmicas, que encetam outras relações de diferença. Uma análise dos vários níveis de oposição no interior do jogo nos revela sua potencialidade polivalente através dos tempos, longe de constituir um modelo estrutural estático e, portanto, vulnerável à acusação de "a-histórico". Assim, procurarei apresentar o palin não como um curioso "costume", uma "sobrevivência" arcaica ou uma "atração" turística — como freqüentemente ele figura na mídia chilena - e sim como manifestação persistente de uma poderosa e expansiva conceitualização indígena das relações sociais. 
Conforme tentarei demonstrar, essa relação de oposição assimétrica corresponde, no contexto do palin, a um reino de socialidade, descrito por Viveiros de Castro como "afinidade potencial". Para este autor, o conceito de afinidade potencial refere-se a um valor simbólico genérico de alteridade, do qual a afinidade real é apenas uma expressão. Ele sugere que para as sociedades ameríndias, a afinidade potencial é um estado default abrangente da socialidade, a partir do qual as relações de identidade (ou, no idioma do parentesco, a "consangüinidade") devem ser construtivamente forjadas. ${ }^{1}$ Assim, "a diferença precede e encompassa a identidade" (2001:25). Essa diferença é ambígua, no sentido de que abrange tanto a diferença negativa do inimigo quanto a diferença positiva do parente afim real, do qual a consangüinidade pode emergir. Na sociedade mapuche, instituições como o casamento e a cooperação econômica englobam o aspecto positivo da afinidade potencial, ao passo que o palin soma-se a elas encompassando o aspecto negativo - o da inimizade e do perigo. A identidade desse afim em potencial, desse Outro paradigmático, depende de ambos os contextos - social e histórico - em que está situada. E creio ser aqui que reside o gênio do palin: ele simultaneamente abrange e constrói uma série de relações de alteridade que se dão em vários níveis distintos. Talvez tenha sido justamente a sua capacidade de criar e abrir estes diversos tipos de relação com diversos tipos de Outros que lhe assegurou a longevidade e sua continuada relevância para os Mapuche. A análise do palin que apresento aqui se baseia na identificação de diferentes níveis de oposição entre o "exterior" e o "interior" dentro do jogo e das trocas sociais que o cercam. Passemos agora do abstrato ao concreto: no plano mais geral, veremos que o palin, como um todo, pode se opor ao que está fora dele. Podemos qualificá-lo como um "interior" de identidade, e o que está fora como um "exterior" de diferença. Porém, dentro do próprio palin, dentro do "interior", também há essa mesma oposição entre "interior" e "exterior" — aquela entre a equipe da casa e a equipe visitante. E se prosseguirmos deste ponto, poderemos ver que há uma relação adicional de "interior" e "exterior" dentro de cada equipe: entre a pessoa e o grupo. Como observou Viveiros de Castro em sua discussão sobre dualismos concêntricos, "qualquer ponto arbitrariamente escolhido do interior é um limite entre um interior e um exterior: não existe meio absoluto de interioridade" (2002:430). É importante ter em mente que todas essas relações de diferença se dão simultaneamente, mas que, dependendo dos contextos histórico e social, certos níveis de diferença tornam-se mais salientes do que outros. Minha sugestão é que essa potencialidade polivalente seja responsável pelo fato de o palin ainda ser relevante para as pessoas, hoje em dia. 
O argumento que apresento neste artigo está organizado centripetamente, como um movimento para dentro a partir de uma série de oposições concêntricas. Ele começa com uma breve descrição da representação mapuche da pessoa (che) e sua relação com as formas coletivas da socialidade mapuche. Passo então a descrever os elementos básicos do palin, tais como os observei durante meu trabalho de campo. Na seção seguinte, exploro as conexões entre este último e a guerra, focando especificamente a importância histórica deste esporte como meio de preparação dos guerreiros e para a formação de alianças militares contra os espanhóis ou contra grupos mapuche hostis; em seguida, exploro, em minha própria etnografia, o modo como o palin pode ser considerado uma forma de guerra simbólica em si mesmo. Por fim, a seção subseqüente explora as conexões entre este esporte e a troca ritual. Em particular, dirijo o olhar para a natureza da relação entre as duas equipes que disputam o jogo e entre os agregados sociais de que elas provêm. Na seção final, vou adiante e descrevo o papel da pessoa dentro do palin, discutindo de que modo a forma de relação com o oponente é, por sua vez, oposta à relação existente entre os dois grupos.

\section{Quem são os Mapuche?}

Os Mapuche são, em suas próprias palavras, "o povo da terra"; mapu significa "terra", e che, "pessoas". Na literatura mais antiga, eles figuram como "Araucanos" em espanhol e "Araucanians" em inglês. De um ponto de vista externo, constituem um grupo cultural e lingüístico relativamente bem definido e surpreendentemente homogêneo. Há muito pouca variação dialetal na língua mapuche - o mapudungun, que muito provavelmente constitui um isolado lingüístico - e as pessoas da costa chilena do Pacífico podem comunicar-se com pessoas dos pampas argentinos sem qualquer dificuldade. Os Mapuche não se enquadram nem na área cultural "andina" nem na "amazônica", as mais estudadas entre os povos ameríndios da América do Sul.

Tendo resistido desde 1536 aos ataques espanhóis e, depois, chilenos, os Mapuche acabaram por sucumbir em 1883. A derrota militar foi seguida por sua fixação em reservas, e o impacto dessa imposição ainda é perceptível hoje em dia. O chefe de cada família tinha de apresentar-se oficialmente à Comissão das Reservas e solicitar as terras que então ocupava, para que um título fosse emitido em seu nome. Entre 1884 e 1929, um total de 3.078 títulos foram emitidos, incorporando cerca de cem mil pessoas. Um número não conhecido de Mapuche permaneceu fora do sistema de reservas, trabalhando como mão-de-obra agrícola nas fazendas chilenas ou migrando para 
as cidades. A posse das terras das reservas era comunal, e elas não podiam ser divididas ou vendidas. Este é um ponto importante, pois o Estado chileno viria a passar a maior parte do século XX tentando reverter este aspecto da legislação, objetivo realizado por um ato do presidente Pinochet, em meados dos anos 80. No entanto, a nova legislação incluiu uma moratória de vinte anos na venda de lotes de terras de reservas a não Mapuches. A Lei Indígena de 1993 tornou essa moratória permanente. Ainda assim, o século XX viu um declínio muito grande da quantidade de terras sob posse mapuche, apesar de que, em teoria, no domínio jurídico, nenhuma terra jamais poderia sair de suas mãos. ${ }^{2}$ Muitas comunidades mapuche estão hoje engajadas em um esforço para retomar terras usurpadas durante a ditadura por empresas florestais e fazendeiros - uma luta que tem se tornado cada vez mais violenta, originando o que ficou conhecido como "Conflicto Mapuche".

A sociedade mapuche contemporânea abrange um amplo espectro: de falantes monolíngües do espanhol, em Santiago, a falantes monolíngües do mapudungun, no coração das terras mapuche, no Chile meridional e do outro lado dos Andes, nas províncias do extremo oeste da Argentina. Hoje, há aproximadamente 1,2 milhões de Mapuche no Chile, e mais cinqüenta mil na Argentina. ${ }^{3}$ Devido à combinação de crescimento populacional rápido e escassez crítica de terras, muitos Mapuche vêem-se forçados a migrar para as cidades, e é nesses centros urbanos que vive, atualmente, mais da metade desta população.

A pesquisa em que se baseia este artigo foi realizada em um istmo de cerca de cinco quilômetros de largura, conhecido como Piedra Alta, espremido entre o lago Budi e o oceano Pacífico. Dados suplementares foram colhidos no distrito vizinho de Isla Huapi, que fica no próprio lago Budi. Piedra Alta é composta por nove reservas contíguas, atualmente conhecidas como "comunidades indígenas", tendo eu residido na de Conoco Budi. Todas as quinze famílias de Conoco tiravam seu sustento da agricultura de subsistência, basicamente batata e trigo. As pessoas vivem em moradias dispersas, situadas nas encostas dos morros, para tentar evitar a lama dos terrenos baixos e o vento que sopra no topo. Em Piedra Alta, a maioria delas é bilíngüe, falante do espanhol e do mapudungun, embora alguns mais velhos falem apenas esta última língua e outros, mais novos, somente a primeira.

\section{A pessoa mapuche}

Antes de descrever o jogo do palin, eu gostaria de oferecer um breve esboço dos tipos de relação que as pessoas mapuche criam e pelos quais também 
são criadas. Esse é um passo necessário à compreensão da relevância do palin para a prática da socialidade mapuche. Ele implica necessariamente uma discussão acerca da "estrutura social" mapuche, tópico que tem sido objeto de muitos debates ao longo dos anos. Para Louis Faron, a sociedade mapuche poderia ser entendida como essencialmente patrilinear (1956, 1961a, 1961b). Este autor argumentou que o confinamento em reservas, pelo Estado chileno, na virada do século XX, cristalizou uma tendência patrilinear preexistente, por ter restringido as possibilidades de migração e, portanto, a fissão e fusão de grupos, e também por ter criado uma situação legal em que um laço de descendência em relação ao fundador da reserva se tornou preponderante. Milan Stuchlik, no entanto, considerou que a implementação do sistema de reservas teve o efeito contrário: a fixidez dos grupos locais teria levado à precedência da proximidade genealógica e espacial, em detrimento dos vínculos de linhagem e, sendo assim, a sociedade mapuche poderia ser melhor conceitualizada como bilateral ou cognática (1976). Esta discordância resulta em grande parte do fato de se tentar compreender a sociedade mapuche em termos dos agregados sociais visíveis, os quais, devido às contingências da história e da geografia, são altamente heterogêneos e variáveis. Parte desta confusão desaparece se tentarmos compreender os agregados sociais da perspectiva do conceito da pessoa. O comentário de Marilyn Strathern relativo às gerações anteriores de etnógrafos da Melanésia é igualmente aplicável aos estudos prévios sobre a sociedade mapuche: "A vida social era, portanto, conceitualizada como a participação da pessoa em uma pluralidade. Como resultado, um indivíduo era sempre apenas uma parte de algum agregado mais abrangente" (1992:86).

Para se ter alguma compreensão da pessoa mapuche e dos agregados sociais a que ela dá origem, é central o conceito mapudungun de küpal, que os Mapuche traduzem para o espanhol como descendencia. ${ }^{4}$ Toda pessoa é produto da combinação do sangue menstrual da mãe e do sêmen do pai. Cada uma dessas substâncias transmite o küpal materno e também o paterno; o sêmen, portanto, liga uma criança aos avós paternos, e o sangue menstrual cria um vínculo com os avós maternos. Os Mapuche dão, assim, grande importância a seus meli folil, ou "quatro raízes" — alusão metafórica aos quatro avós. O küpal é considerado um componente "dado" da pessoa: fixo, imutável e permanente desde o momento da concepção. Sua influência é visível nas características físicas de cada um, nas suas relações com os espíritos, em sua capacidade de desempenhar certos papéis sociais e no comportamento moral.

Além de ser um aspecto essencial da pessoa, o küpal também pode ser entendido como base de uma relação interpessoal. Assim, pode-se di- 
zer de alguém que ele "compartilha" o küpal com todos os seus parentes consangüíneos. Porém, embora em um nível o conceito sugira uma teoria de descendência cognática ou bilateral, em termos de compartilhamento o termo küpal adquire um viés patrilinear bem definido. O fato de haver uma tendência virilocal implica que os homens passem a maior parte de suas vidas com aqueles com quem compartilham o küpal, ao passo que as mulheres casadas tendem a ser separadas, social e espacialmente, desta categoria de pessoas. O conceito bilateral de küpal, portanto, torna-se patrilinear quando seu significado é estendido do nível de componente da pessoa para o das relações interpessoais. A co-residência de homens, mulheres solteiras e crianças que compartilham o küpal remete à idéia de serem kiñe küpal, "da mesma descendência". As relações entre tais "co-residentes patrilinearmente relacionados" que compartilham o küpal baseiam-se numa noção de similaridade e identidade que leva a uma ética de solidariedade e auxílio mútuo obrigatórios. Estas relações, no entanto, também são freqüentemente carregadas de problemas, especialmente na medida em que se articulam em torno de tentativas de afirmação de autoridade entre diferentes gerações e no interior de cada uma - tentativas estas que desafiam a autonomia fundamental da pessoa mapuche.

As relações matrilaterais são designadas como küpal ñuke püle, literalmente, "descendência pela mãe". Elas se caracterizam pela diferença aparente e a igualdade pressuposta. As pessoas entram em relações de troca com seus parentes matrilaterais, ao passo que muito raramente o fazem com os parentes patrilaterais. Relações criadas por intermédio do casamento geralmente se assemelham àquelas entre os parentes matrilaterais. De fato, a união entre primos cruzados matrilaterais (ñukentun) era, anteriormente, a forma idealizada e preferível de casamento. Portanto, o conceito de küpal faz referência a muitas coisas - tanto a um aspecto essencial da pessoa quanto à forma de certas relações; tanto a relações patrilineares quanto a relações cognáticas. Talvez tenha sido o caráter polissêmico deste aspecto central da pessoa que levou à confusão entre os etnógrafos que procuraram entender a pessoa a partir dos agregados sociais a que ela pertence.

Relações de identidade entre pessoas de kiñe küpal são um fator-chave na composição de "grupos" como comunidades [em espanhol, no original] e lof $_{,}{ }^{5}$ que terão relevância em nossa discussão sobre o palin. O termo espanhol comunidad designa, no contexto mapuche, o grupo legalmente constituído das pessoas que residem em uma reserva, e o termo mapuche lof designa um grupo localizado, que pode se estender por uma ou mais reservas. ${ }^{6}$ Kiñe küpal, lof e comunidad são sinônimos em alguns casos, mas nem sempre. Podemos generalizar e afirmar que comunidad é primariamente 
um conceito jurídico, lof, um conceito territorial e kiñe küpal, um conceito de parentesco.

Contudo, em toda esta discussão da pessoa mapuche e dos agregados sociais a que alguns de seus aspectos dão origem, um fato crucial é omitido: ${ }^{7}$ que, para ser uma verdadeira pessoa, para ser che, é preciso ir além das relações com os parentes, sejam elas por linha materna ou paterna. Ainda que estas sejam cronologicamente anteriores, são as relações criadas por vontade própria ao longo da vida que permitem a alguém ser uma pessoa. A forma paradigmática destas relações é a troca de vinho entre amigos homens (wenüy). Tal troca é, idealmente, de reciprocidade, e se dá nos rituais de fertilidade chamados ngillatun, em funerais, em interações cotidianas e principalmente, para nossos propósitos aqui, nos jogos do palin. ${ }^{8}$ Não há como exagerar a importância dos amigos, já que é por meio da ativação da capacidade de formar relações com não-parentes que alguém se torna uma verdadeira pessoa. ${ }^{9}$ Essa conceitualização da pessoa é claramente aberta e orientada para o exterior, para os outros. Na verdade, a pessoa mapuche poderia ser descrita de forma precisa como centrífuga - um movimento constante para fora, tanto em termos metafóricos de proximidade genealógica quanto no sentido literal do espaço geográfico. Nessa conceitualização da pessoa ressoa a descrição dos Araweté, feita por Viveiros de Castro, como "seres de devir" (1992:252).

Este esboço da pessoa e da "estrutura social" dos Mapuche teve forçosamente de ser breve e superficial. No entanto, espero que tenham ficado evidentes três pontos-chave que terão relação com a análise do palin, mais adiante. Em primeiro lugar, a "sociedade" e os acontecimentos sociais, como este jogo, são entendidos como efeitos das pessoas, e não o contrário. Em segundo lugar, a própria pessoa é conceitualizada pelos Mapuche como um ponto de contato entre um "interior" de identidade consangüínea e um "exterior" da diferença em relação aos afins e amigos. Esses valores de identidade e diferença expressam-se em termos como kiñe, literalmente, "de alguém", e ka ou kangelu, "outro". Finalmente, em terceiro lugar, espero ter mostrado que a pessoa pode ser conceitualizada (e o é, entre os Mapuche) como um projeto em curso, um projeto de auto-criação, para o qual o palin, como veremos, constitui uma arena privilegiada.

\section{Os elementos básicos do palin}

O palin é um jogo superficialmente similar ao hóquei na grama - a diferença mais marcante consistindo no fato dele ser jogado em um cam- 
po muito comprido, porém estreito, chamado paliwe, em mapudungun. Há muita variação regional nas dimensões do campo de jogo, mas em Piedra Alta e Huapi, ele tem quase sempre 200 trekan, "passos", de comprimento e apenas oito trekan de largura. As laterais são chamadas kachi e as linhas de fundo, pelas quais a bola deve passar para que seja marcado um ponto, são as tripalwe, termo que significa literalmente "lugar de saída". Os limites do campo de jogo são demarcados por varas de uma planta conhecida em mapudungun como maki ou külong (Aristotelia chilensis). A única marcação no próprio campo é um pequeno monte de terra que indica o ponto central, chamado shungülwe. Na prática, atualmente, qualquer trecho de terreno mais ou menos plano, não cultivado e de dimensões adequadas pode ser usado como campo de jogo. Esses lugares às vezes são reconhecidos pelas autoridades chilenas como sitios sagrados, juntamente com os cemitérios e os locais do ritual de fertilidade, ngillatun.

As duas equipes podem ser constituídas por nove, onze ou treze jogadores, cada uma. O número é combinado pelos dois "capitães" (ñidol) antes do início do jogo. O importante é que haja um número ímpar, nüni, em cada lado. É isso que garante que haja um número igual de jogadores de cada lado do jogador central, o shüngulfe. Além disso, considera-se auspicioso o fato de o número de jogadores de cada equipe ser ímpar.

Cada jogador ocupa uma posição distinta. O shüngulfe é aquele que enfrenta o shüngulfe adversário, tentando tirar a bola do centro para começar cada jogada. Esta função é geralmente ocupada pelo ñidol, o capitão. Em frente ao shüngulfe e atrás dele, formando uma fileira, ficam os jogadores de meio-campo, os inantuku. Sua tarefa é fazer com que a bola avance rapidamente na direção da meta adversária e impedir que os oponentes correspondentes façam o mesmo. Assim que a bola é arremessada para cima e para a frente, o atacante, ütrünentu, vai ao seu encalço. O adversário que ocupa a posição oposta é o kachintuku, o defensor, que tenta barrar o ütrünentu e fazer com que a bola saia pela lateral. Cada jogador maneja seu wüño, um bastão que se assemelha a um de hóquei bem fino. ${ }^{10} \mathrm{~A}$ bola, designada como pali, é feita de lã compactamente enrolada, envolvida em couro.

A forma básica do palin, tal como praticado junto ao lago Budi, é quase sempre a mesma, embora haja pequenas variações, conforme o jogo seja o palin normal, kayñetu, "palin do inimigo", ou purrun palin, "palin dançado". As variações entre estes tipos são mais ou menos padronizadas, mas alguns detalhes são definidos pelo capitão de cada equipe. O objetivo, neste jogo, é marcar pontos golpeando a bola e fazendo-a cruzar a meta adversária. Se a bola sai pelas laterais, o jogo recomeça do centro - o que freqüentemente acontece, dado o formato estreito do campo de jogo, sendo preciso reiniciar 
Figura 1: diagrama do palin

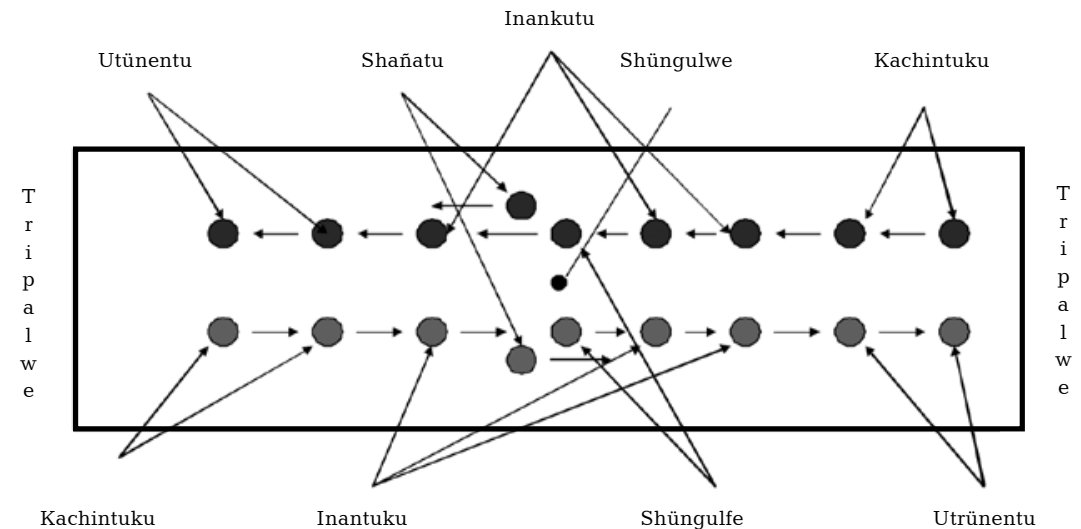

a partida várias vezes até que se marque um ponto. Uma equipe deve marcar quatro pontos consecutivos (sem que o adversário também marque um) para conquistar kiñe kuden, "um jogo". Os pontos marcados pela equipe que está perdendo reduzem também o total de pontos da equipe que está em vantagem no marcador. Assim, se uma equipe está vencendo por três pontos [a zero] e sofre um gol, seu marcador cai para dois.

Adiante, discutiremos os diferentes contextos em que kayñetu, palin normal e purrun palin são realizados, mas vale a pena deixar indicado que as variações aparentes na forma são na verdade apenas modificações das trocas sociais. As partidas do palin normal e do purrun palin com freqüência terminam sem definição, com o time que está em vantagem não conseguindo obter diferença maior do que um ou dois pontos em relação ao adversário. Nesse caso, declara-se empate, designado em mapudungun como ngelay wewün, "sem vitória". Não há árbitros, e qualquer discordância que surja tem de ser resolvida entre as duas equipes, lideradas por seus respectivos ñidol.

\section{Mapuche versus winka}

O restante deste artigo discutirá as relações de diferença dentro do jogo. Contudo, nesta seção meu foco recai sobre a oposição entre o complexo do palin como um todo e tudo mais que lhe é exterior, uma relação que freqüentemente tem se manifestado como oposição étnica entre Mapuche e winka o termo nativo para os não-Mapuche. ${ }^{11}$ Este papel do jogo na marcação de limites da etnicidade mapuche se faz notar, primeiramente, por meio de sua 
conexão histórica com a guerra, tanto por seu uso em treinamento militar quanto por constituir a ocasião em que se formavam as alianças militares contra winka. A natureza do palin como um termo nesta relação entre winka e Mapuche continua presente no uso deste jogo como marcador-chave da identidade política e étnica deste povo.

\section{O palin como exercício militar}

A história da supremacia militar e da resistência dos Mapuche aos espanhóis é bem conhecida e bem documentada. Com efeito, ela se transmitiu, vindo a tornar-se um dos grandes pilares da identidade nacional chilena. ${ }^{12}$ No entanto, há ainda hoje um quê de mistério na questão de como um grupo largamente disperso de horticultores nômades, sem uma "estrutura social" hierárquica estabelecida, pôde alcançar tal feito. Talvez uma pista esteja no modo como a própria formação da pessoa mapuche estava embebida em um ethos da atividade guerreira. Várias fontes históricas revelam o papel do palin dentro deste sistema de preparação militar.

Manuel Manquilef foi um professor de escola mapuche, que escreveu após a derrota militar final deste grupo, e seus Comentarios del pueblo araucano (1914) ainda são, possivelmente, o melhor material etnográfico disponível sobre este povo, naquela época. É significativo o fato de que os etnógrafos não-nativos do período - como Guevara $(1908,1925)$ e Latcham (1924) — tenham lidado com os temas padrão de parentesco e religião, ao passo que Manquilef dedicou todo o segundo volume de seu trabalho a la jimnasia nacional. Muitos dos esportes documentados na obra são, de fato, exercícios militares, e Manquilef emprega os termos espanhóis ejercicio militar e juego intercambiando-os. Para ele, estes jogos constituiriam o principal meio de educar a juventude mapuche dentro de um modo de vida militar, e seria por seu intermédio que se alcançariam as proezas: "Os exercícios militares tornaram os índios aptos a superar todas as dificuldades e os perigos, a vencer com ousadia, em campo aberto, os obstáculos do conquistador inteligente e audaz" (1914:24). Apesar do tom ligeiramente romântico, Manquilef fornece relatos detalhados e de primeira mão sobre todo o espectro dos exercícios, cobrindo desde aqueles puramente militares (treinamentos com lança, com maça, tiro ao alvo), passando pelos exercícios físicos (corrida, natação, levantamento de peso, luta), até o palin, que servia para desenvolver as habilidades mentais e físicas do guerreiro. Não eram, porém, apenas os Mapuche que estavam cônscios do significado do jogo na constituição da força militar. Já em 1674, o cronista espanhol Rosales 
observou que "por meio dele [palin] eles se preparam para a guerra" (1989 [1674]:169). Leotardo Matus, que escreveu sobre o palin no século XIX, comentou que "as autoridades espanholas sempre acreditaram que no jogo da 'chueca' encontrava-se a mais poderosa arma da dominação araucana; e não estavam equivocados" (apud Manquilef 1914:83).

Os Mapuche atuais têm consciência da importância militar do palin no passado. Embora nenhuma das pessoas que conheci tenha tido qualquer experiência de guerra, muitas haviam servido no Exército chileno e mostravam segurança ao afirmar os tipos de qualidades que os guerreiros devem ter. Esta fonte de informação coexistia com as memórias dos mais velhos a respeito dos diversos feitos militares que ouviram de seus avós. Era por meio do palin, disseram meus informantes, que se alcançava a força física e mental necessária para a guerra. O palin, segundo eles, torna as pessoas yafulkülen, "firmes", e kulfunkülen, "alertas", e eles afirmam que essas qualidades foram fundamentais para a sobrevivência militar mapuche. Há concordância entre as fontes históricas e os Mapuche atuais no reconhecimento de que o palin servia como preparação do guerreiro para as dificuldades e as necessidades inerentes à guerra.

\section{O palin como instituição política}

O palin era útil aos propósitos militares dos Mapuche, não apenas como meio de preparação física e psicológica dos homens para a guerra, mas também por ser a ocasião em que as alianças militares se formavam. Isto fica mais evidente no vínculo que há entre este jogo e os trawun, encontros em que se chegava a um consenso a respeito de qualquer ação política ou militar a ser empreendida contra terceiros. Os trawun costumavam realizarse quase sempre no mesmo local, e os mais velhos, em Piedra Alta, ainda lembram o lugar específico dos trawun nessa localidade: um ponto elevado e exposto, sob um grande loureiro. Há várias referências, na literatura, ao fato de o lugar dos trawun e do palin ser o mesmo (Ñanculef 1993:7; Manquilef 1914:73). O palin, ao que parece, era tanto ocasião quanto meio de criação de alianças entre grupos mapuche. Em um palin de 1911, um capitão, ñidol, deu início a um discurso cerimonial com as seguintes palavras: "Bom amigo: de acordo com as tradições que preservamos de nossos pais e avós, eram os jogos que nos uniam na amizade que hoje nos distingue" (apud Manquilef 1914:73). Era dessas alianças que nascia o poderio militar mapuche, algo que os espanhóis claramente percebiam. O seguinte relato de Diego de Rosales é o primeiro de muitos, ao longo dos séculos, a apontar a conexão entre o palin e as alianças militares: 
Após este jogo, eles sentam-se para beber e têm uma grande rodada de chicha; é desses jogos de chueca [o palin] que resultam revoltas previamente combinadas, e é com esse propósito que eles reúnem todos da terra, e à noite falam e combinam revoltar-se (1989 [1674]:170).

Não é surpresa, portanto, que os espanhóis, no território sob seu controle, tenham feito tantas tentativas de reprimir e eliminar a prática do palin. O jogo foi proibido em 1647 pelo governador Mujica e em 1763 o bispo Aldai declarou-o passível de punição com excomunhão (Manquilef 1914:67). Ainda assim, nos séculos que se seguiram à cessação da guerra aberta, após a Paz de Quillín, em 1642, os próprios espanhóis se viram forçados a consentir uma situação em que, para criar alianças com os líderes militares mapuche ao longo da fronteira, tinham de aceitar o palin. Há registros da realização do jogo nas negociações de Negrete, em 1771, e de Trapiwe, em 1774 (Ñanculef 1993:7). Vemos, assim, que a criação das alianças militares que permitiam a Mapuche dispersos constituir poderosa força militar estava estreitamente ligada ao palin.

O jogo do palin, portanto, serviu no passado como marcador da fronteira entre o interior mapuche e um exterior de outros, de não-Mapuches. Isto se evidencia na criação de um tipo específico de ética militarista, na relação íntima do palin com os aspectos rituais da guerra e no seu papel como lugar de alianças militares e de cooperação. Neste nível de análise, a relação de aliança assimétrica não se encontra no complexo do palin, e sim entre este jogo e tudo que o envolve e o abrange. Seu papel no delineamento da fronteira entre Mapuche e winka continua até hoje, na medida em que o palin aparece como um dos símbolos paradigmáticos da identidade deste grupo. Os torneios que se realizam no coração das terras mapuche, bem como em Santiago, são com freqüência palco de discursos altamente políticos a respeito da retomada dos territórios confiscados sob a ditadura Pinochet, e mesmo antes. Esta associação é reforçada pela prática de se carregar os wüño, bastões do palin, em quase todos os encontros políticos e outras reuniões comunitárias, nos quais costuma-se fazê-los entrechocarem-se no ar para expressar concordância com o discurso de determinado orador.

\section{Nós e eles}

Na seção anterior, descrevi o modo pelo qual o palin serve como instrumento de unificação contra um outro que é exterior, que aparece como um entre dois elementos em oposição. Nesta seção, exploro a relação-chave de diferença 
opositiva dentro do próprio palin, a saber, a que existe entre as duas equipes que disputam a partida — uma distinção freqüentemente apresentada como aquela entre "nós" (inchiñ) e "eles" (kache). No que diz respeito ao próprio jogo, a oposição é representada como um conflito violento e estreitamente relacionado à guerra; entretanto, no nível das duas comunidades que se opõem, sua representação se dá pelo ritual e pela troca. Iniciarei explorando os elementos que nos permitem entender o jogo como conflito: sua violência intrínseca, sua relação com os costumes de guerra, seu poder de matar.

O palin é um jogo com alto grau de contato físico e em que freqüentemente ocorrem ferimentos e contusões. Os jogadores tentam dominar a bola com trancos de ombro em seus oponentes, recurso chamado de lünkuwun. As piores contusões se dão quando os jogadores golpeiam furiosamente a bola em movimento, no ar. No local em que fiz trabalho de campo, pelo menos três homens mais velhos perderam um olho desta maneira. Os mais velhos lembram-se da época em que os Mapuche usavam cabelos compridos e, para dominar a bola, os jogadores derrubavam os oponentes puxando-os pelos rabos-de-cavalo; no entanto, o corte mais curto pôs fim a este aspecto do jogo. Durante a partida, os jogadores incitam-se usando frases idiomáticas que se referem a aspectos técnicos da disputa com o adversário, como, por exemplo: kumetungafuimi, "vigiar de perto o seu kon [oponente]", ou trefkuñefinge , "empurrar o adversário". A violência não é circunstancial, mas um dos componentes intrínsecos do palin. Sempre me asseguraram de que se deve jogar com violência, pois, do contrário, o adversário se sentirá insultado. De fato, um dos insultos mais comuns entre aqueles que os espectadores costumam gritar é nielaymi tami kon, "você não tem adversário". Um relato antigo, de Pedro de Córdoba y Figueroa, afirma que "o jogo raramente termina sem que se derrame sangue" (1862 [1740]:30).

Todavia, o alto grau de violência, por si só, não basta para justificar que se descreva o palin como uma forma de prática de guerra. Há mais indícios, provenientes de fontes históricas, que vinculam certas modalidades deste jogo às práticas guerreiras. Manquilef menciona que a equipe que estava perdendo animava-se com os gritos de "faremos crânios com as suas cabeças mortas" (1914:76), o que parece referir-se ao costume, bem documentado, de se prepararem vasilhas para bebidas com os crânios de prisioneiros de guerra (Cooper 1946:731). Junto ao lago Budi, os jogadores ainda são convocados pelo kull-kull, uma espécie de trompa feita de chifre de boi. Este instrumento é geralmente descrito pelos Mapuche, em espanhol, como corneta de guerra, e seu uso como meio de chamamento à guerra está referido em várias fontes (Titiev 1951:126; Nanculef 1993:10; Manquilef 1914:77). Na descrição de Ñanculef da inauguração de um novo campo de jogo há menção à entoação de canções guerreiras e aos gritos de guerra emitidos pelos jogadores durante a demarcação do campo 
(1993:12). Segundo Guevara, tanto os jogadores do palin quanto os guerreiros abstinham-se sexualmente antes de participarem destas atividades (1908). Outras evidências são fornecidas por Titiev, ao afirmar que "tão completamente entrelaçados estão os conceitos de guerra e de hóquei [palin] que, ao falar dos seguidores de um lonko [chefe], mais de um informante empregou indistintamente os termos de guerreiro e de jogador de hóquei" (1951:125).

Os dados históricos sugerem que já há bastante tempo o palin vem sendo simbolicamente associado à guerra, por meio de uma série de práticas. Porém, há também um sentido a partir do qual se pode afirmar que este jogo consiste em uma verdadeira atividade guerreira, uma vez que, segundo meus informantes, "ele causa baixas em um sentido bem real". Isto se aplica especialmente ao caso do purrun palin, o "palin dançado", a forma mais elaborada entre as que compõem o espectro do jogo. Sempre que falam do purrun palin, as pessoas enfatizam o alto grau de perigo implicado em sua realização. Ele é, literalmente, um jogo de vida ou morte. Um membro do lof da equipe perdedora - geralmente um parente patrilinear próximo do capitão ou de um dos melhores jogadores - morrerá dentro de alguns meses após a derrota. Embora a morte sempre se dê de modo indireto, ela é considerada um efeito direto do resultado do jogo. Anteriormente, a vida de um membro do lof era apostada pelo ñidol, o "capitão" de cada equipe. Hoje, ainda estão vivas pessoas conhecidas por se recusarem a realizar o palin sem que a vida de alguém estivesse em jogo. Elas são por vezes descritas como as "verdadeiras palife". É interessante notar que, embora já não se pratique o purrun palin pondo em jogo vidas de pessoas, ele ainda é considerado como causa inevitável de mortes no lof da equipe derrotada. Esta é a razão por que quase todos os purrun palin são predeterminados a terminarem empatados, o que é feito combinando-se uma série de muitos sets que os ñidol sabem que não será possível completar em um único dia de jogo. ${ }^{13}$ Não se podendo apontar uma equipe perdedora, espera-se com isso evitar a morte que a derrota inevitavelmente viria a provocar. Tanto o palin comum quanto o purrun palin são adiados se alguém do lof visitante ou do lof local estiver doente, entendendo-se que a realização de um palin seria desrespeitosa ao doente e o poria em perigo ainda maior. Dada a importância do resultado do palin, não surpreende que esteja cercado de certas práticas ocultas, cuja intenção é modificar-lhe o resultado por meios sobrenaturais. Este tipo de feitiçaria inclui o ato de enterrar a bexiga (ütrüm) de um animal, especialmente preparada, em uma das extremidades do campo, sob um ramo de maki, para evitar que a bola passe por ali.

Assim como a guerra convencional, também o palin era um meio de resolver alguma discórdia. Os Mapuche mais velhos afirmam que, no passado, o jogo era freqüentemente usado para solucionar conflitos surgidos em torno 
de desacordos territoriais, do rapto de mulheres, ou de desavenças políticas. O resultado do palin era considerado favorável à posição do lof vitorioso. Há um relato famoso de um caso deste tipo, que se deu próximo ao lago Budi, registrado nas Memorias de un cacique mapuche, de Pascual Coña (1984 [1930]), ditadas ao padre bávaro Wilhelm de Moesbach em 1927:

E assim se deu, muito tempo atrás, na Missão de Purulón. Havia aqueles que queriam matar o padre Octaviano; outros diziam que ele não deveria ser morto. Então os que odiavam o padre disseram: "Realizemos um palin; se vencermos, nossa vontade será feita: ele será morto". Realizaram o palin. A equipe favorável ao padre venceu, e ele sobreviveu, junto com sua missão. "Essa deve ser a vontade de Deus", disseram (1984 [1930]:43).

A imposição do colonialismo chileno e do sistema judicial correspondente representou o fim efetivo da resolução autônoma de conflitos entre os Mapuche e, com isso, a morte desta função do palin. No entanto, as pessoas junto ao lago Budi ainda estão conscientes desta função passada e do fato de que o jogo pode efetivamente causar mortes.

Vemos que o aspecto militar do palin cria uma relação de diferença assimétrica entre um "interior" da equipe local e um "exterior" da equipe visitante. Passo agora a explorar o modo pelo qual o aspecto ritual igualmente cria uma relação de diferença entre um "interior", constituído pelo lof local, e um "exterior", constituído pelo lof visitante. Darei atenção especial ao purrun palin, a mais elaborada das três formas principais deste esporte. Veremos que o ritual em torno do purrun palin opera, num primeiro momento, ressaltando a diferença entre os dois grupos, eliminando-a a seguir, apenas para que ela possa novamente ser criada. Como na maioria dos jogos, o resultado não pode ser previsto. Isso parece ir de encontro a certas idéias acerca da "fixidez" do ritual, ou ao menos contra a aplicabilidade de idéias deste tipo aos jogos ritualísticos comumente observados em toda a América indígena. De fato, entender este tipo de jogo como um ritual essencialmente aberto talvez sirva como explicação para sua predominância nas culturas ameríndias dominadas pelo que Lévi-Strauss chamou de "abertura para o exterior" (1996:231).

\section{O purrun palin}

A encenação do purrun palin é considerada um empreendimento complexo, de exigências monumentais. Além disso, ele é visto como inerentemente perigoso para todos os participantes. A palavra purrun significa "dança" 
e, mais especificamente, "dança cerimonial", analogamente ao espanhol bailar, que tende a ser usado como referência a outros tipos de dança. O purrun palin é assim chamado devido às extensas danças que o precedem e o acompanham. Apesar de ocorrer raramente, ele é um dos assuntos favoritos das conversas dos mais velhos. Muitos salientam que os purrun palin atuais não são como os do passado, e que as pessoas que os organizam hoje em dia, embora dignas de louvor por seu esforço em manter a tradição, não têm, como elas mesmas admitem, conhecimento suficientemente minucioso dos costumes, regulamentos e detalhes necessários para que o palin possa sempre küme tripay, "terminar bem".

Para que o evento possa ser realizado, o capitão, ñidol, encarregado da organização deve garantir que tem inteiro apoio moral e material de seu lof. O lof local arca com grandes custos, sendo não somente responsável pela hospitalidade para com o lof visitante, como devendo recorrer aos serviços de várias pessoas para que o purrun palin prossiga. Aí se incluem músicos que tocam diversos instrumentos tradicionais: o tambor conhecido como kültrung ou rali, o trutruka, espécie de instrumento feito de chifre de boi e de um pedaço de mangueira, e a trompa, kull-kull. ${ }^{14}$ Geralmente, podem-se encontrar dentro do próprio lof aqueles que tocam kull-kull e trutruka, mas é possível que grandes esforços sejam feitos para se contratar músicos de fora já que, quanto maior o barulho, mais "belo" é o purrun palin. Todos os músicos de fora do lof são pagos com vinho, alimentos e, em alguns casos, dinheiro. Outros que devem ser contratados são os palhaços, kollong elemento vital da beleza do purrun palin. A palavra kollong designa tanto um tipo específico de máscara quanto aqueles que a usam. Cada lof traz quatro kollong, cuja função é manter a separação entre o lof anfitrião e o lof visitante durante a dança, evitar que pessoas entrem no campo de jogo no decorrer da partida, e entreter o público. Os kollong usam roupas sujas e surradas que contrastam fortemente com as esporas e arreios lustrosos dos cavalos-de-pau que montam. Eles também usam máscaras de couro, que são bastante simples, a não ser pelo bigode longo e recurvado e pelo cavanhaque, ambos feitos com crina de cavalo. Os Mapuche raramente deixam crescer os pêlos faciais, de modo que os bigodes e as barbas dos kollong servem para identificá-los como winka, "brancos". ${ }^{15}$

Nos dias que precedem o purrun palin, as pessoas do lof anfitrião ocupam-se dos preparativos para receber hospitaleiramente os visitantes que virão - tanto os do lof contra o qual o palin será disputado quanto de outros lof dos arredores. A maioria das famílias participantes abaterá pelo menos um porco ou carneiro. Os ñidol geralmente abatem mais animais, já que terão grande número de convidados aos quais devem oferecer comida. 
De manhã cedo, no dia do palin, as famílias anfitriãs partem para o campo de jogo em carros de boi cheios de mesas, cadeiras, panelas, lenha, alimentos e vinho. Lá chegando, cada uma das famílias arruma suas mesas ao longo de um dos lados do campo. As mulheres começam a fazer fogo, preparar cozidos e pães. As pessoas do lof convidado geralmente começam a chegar logo após seus anfitriões e vão alinhando seus carros de boi ao longo da linha lateral oposta, no campo de jogo. Desamarram os bois e sentam-se, esperando pacientemente que a dança tenha início.

Anfitriões e convidados têm cada um seu próprio rewe, altar construído com külong ou maki (Aristotelia chilensis). ${ }^{16}$ Os dois altares ficam situados nas extremidades opostas do campo de jogo. Quando já chegaram pessoas em número suficiente, os membros de cada lof que não estejam diretamente ocupados na preparação dos alimentos começam a dançar em círculos, em sentido anti-horário, em torno de seus respectivos altares. Há, neste estágio, uma grande distância entre os dois grupos de dançarinos, e o ritmo seguido por um deles pode não ser ouvido pelo outro. Cada grupo é formado por duas fileiras - uma de homens, outra de mulheres - que dançam ombro a ombro e vão agitando um ramo de maki; os diversos músicos ficam junto aos dançarinos. A dança dos anfitriões e a dos visitantes são quase idênticas: a única diferença é que a dos primeiros é conduzida ao ritmo do kültrung, o tambor de pele. Após algum tempo, aquele que toca o tambor entre os anfitriões separa-se do movimento em torno do altar e puxa a fila de dançarinos na direção dos visitantes, que circundam seu próprio altar. Os dois grupos fundem-se e são guiados pelo tocador do kültrung até o altar central, por vezes designado dungulme, em volta do qual todos dançam. Após quatro voltas em torno do altar central, os visitantes e anfitriões se separam e formam dois grupos que se defrontam, transversais às laterais do campo. Cada grupo ainda está formado por duas fileiras: a primeira, de mulheres, e a segunda, de homens. Os dois grupos dançam frente a frente e, no espaço entre eles, os dois grupos de kollong, os palhaços, vão e vêm montados em seus cavalos de imitação, garantindo que os dois lof não se misturem, e disputando entre si para ver quem diverte mais os dançarinos.

Quando a dança termina, todos do lof visitante, homens e mulheres, alinham-se lado a lado, defronte dos anfitriões, num tipo de formação hierárquica conhecido como wepulkun. O ñidol dos anfitriões, então, leva seu lof em fila para saudar os visitantes, que aguardam. Ele começa da extremidade direita da fila e vai cumprimentando com apertos de mãos e saudações cada um dos visitantes, seguido de todos os demais do seu lof, que vão também percorrendo a fila dos visitantes e trocando a saudação mapuche usual do mari-mari. Essa parte do palin é conhecida como chalin, "saudação" e, 
assim como os cumprimentos cotidianos, é levada muito a sério por todos os envolvidos. Após o chalin, o capitão, ñidol, vai até o ñidol do outro grupo e lhe diz que prepare seus jogadores.

No purrun palin, a forma do jogo propriamente dita é idêntica à do palin usual, anteriormente descrito. O número de pontos necessários para vencer é estabelecido pelos dois ñidol antes do início do jogo. Durante o andamento da partida, quatro pares de meninas — dois para cada equipe dançam junto à lateral, no meio do campo, cantando alto "faw püle pali", "venha por aqui, bola!". Elas são chamadas mütrumpalife, "aquelas que chamam a bola", e vestem roupas mapuche tradicionais, agitando ramos de maki. As mulheres mais velhas com freqüência reúnem-se próximo à meta do adversário e chamam a bola em voz alta, para que passe por ali. Ñanculef refere-se a esta prática, em mapudungun, como maichipalin (1993:5) ${ }^{17}$

A relação de oposição que se dá no nível do grupo toma duas formas ligeiramente distintas: a oposição entre as duas equipes é vista como intrinsecamente guerreira, ao passo que aquela entre os dois lof é expressa por meio da dança ritual. Porém, em última instância, tanto o jogo propriamente dito quanto a dança que o acompanha têm o mesmo efeito: uma morte no lof da equipe perdedora. Para muitos participantes, a inevitabilidade dessa morte faz vacilar o desejo de se obter um equilíbrio entre os dois lof e tentar impedir que tal morte ocorra. Em outras palavras, a simetria desejada pelas pessoas é solapada pela assimetria inerente ao próprio palin — uma assimetria que, ironicamente, leva a uma proliferação continuada de retribuição e, em certo sentido, vingança.

\section{O palin e a pessoa}

Nesta seção, mostro de que maneira o palin compreende relações de diferença, não apenas entre níveis distintos dos grupos, conforme rapidamente descrito nas seções anteriores, mas também entre pessoas e, além disso, entre pessoas e grupos. É claro que se poderia argumentar que essas tais entram em relação apenas na qualidade de representantes, ou unidades mínimas, dos grupos a que pertencem. No entanto, não creio que seja este o caso. Sugerirei que no palin, assim como no caso do parentesco mapuche já discutido acima, a pessoa é representada como anterior ao grupo. Este deslocamento da ênfase ocorre no próprio jogo e também nas trocas sociais que o cercam. Assim, relações entre grupos são representadas pelos Mapuche como efeito cumulativo de relações entre pessoas, e não o inverso. Iniciarei examinando o modo como surgem os ciclos de palin, ressaltando 
que o desafio inicial gerador do ciclo é visto como algo repetido por todos os indivíduos que entram na disputa. Passarei então a examinar a natureza da relação entre oponentes individuais, chamados de konwen ou kayñewen, antes de observar de que modo a estrutura do jogo se presta melhor à análise como acumulação de uma série de disputas individuais, e não como um "jogo de equipe" no sentido usual da expressão. Uma evidência adicional provém das relações de reciprocidade existentes entre oponentes e no modo como diferem das relações de reciprocidade generalizada que há entre grupos. Concluo a seção examinando o kayñetu, uma forma de palin em que a relação de oposição chega ao nível mínimo.

\section{O início do ciclo}

Anteriormente, apenas os chefes, lonko, podiam organizar o palin, mas atualmente qualquer um pode angariar apoio suficiente, dentro do seu lof, para fazê-lo. O desafio só é lançado depois que o futuro capitão se assegura de que possui, de fato, tal apoio. A pessoa desafiada pelo capitão, ñidol, será alguém que ele acredite capaz de arregimentar apoio suficiente em seu lof para aceitar o desafio. Este último geralmente é feito entre amigos próximos, com pouca diferença de idade e de posição social. É importante salientar que o desafio e a subseqüente combinação da realização do palin são considerados algo que se dá entre duas pessoas, não entre dois lof. A busca de apoio empreendida pelo ñidol consiste em certificar-se de que outros membros do seu lof estão dispostos a fazer seus próprios desafios paralelos a pessoas do outro lof. Se as pessoas sentem que não têm oponentes potenciais para desafiar, não darão apoio à tentativa do ñidol e sugerirão um desafio contra outro lof. A palavra "desafio" talvez não expresse bem a delicadeza e o tato com que se faz a proposta do palin. Várias sugestões, em caráter tentativo e entremeadas de conversas vagas sobre preços agrícolas ou o bem-estar dos parentes aos poucos vão se acumulando até que se chega a uma combinação. Os motivos para recusar uma proposta de palin são falta de dinheiro, obrigação prévia de "retribuir", e alguma doença ou morte recente no lof. Se o desafio é aceito, no entanto, o jogo será marcado para uma data dentro do período de um ano — os palin quase sempre ocorrem no inverno, de modo que os desafios correspondentes foram geralmente feitos no verão anterior.

Algumas semanas antes da data prevista para a realização do palin, faz-se no território do lof convidado um jogo informal, de treinamento. A intenção é permitir que os homens de cada lof encontrem seus respectivos 
adversários e possam assim criar o par de opostos konwen ou kayñewen. Cada um geralmente procura um adversário que seja um amigo próximo e que tenha a mesma idade, condição física e financeira. Nesse palin de treinamento, não há oferecimento de bebida nem de comida, embora se formem muitos grupos informais que bebem juntos, depois de terminado o treinamento. Os desafios feitos no palin de treinamento são considerados paralelos ao desafio e à combinação que já houve entre os dois ñidol. Ele permite que os homens façam individualmente seus próprios desafios a outros homens. Pequenas apostas de vinho ou cidra consolidam a relação de konwen em que se acaba de ingressar. Sem esse relacionamento, não se pode participar do palin.

\section{A pessoa dentro do jogo}

Detenhamo-nos em explorar com mais minúcia aquilo que seria a relação konwen ou kayñewen. Os Mapuche geralmente traduzem a palavra kon pelo espanhol amigo, e kayñe como enemigo ["inimigo"]. Cada par de adversários que se defronta é conhecido como kayñewen ou konwen, sendo que wen é um sufixo que implica a idéia de relação mútua. O fato de as pessoas usarem as palavras kon e kayñe de modo mais ou menos intercambiável pode parecer inusitado ao leitor, uma vez que amizade e inimizade [ou hostilidade] são vistas no Ocidente como valores antonímicos. Quero sugerir, aqui, que kon/kayñe é um exemplo perfeito do "afim potencial" descrito por Viveiros de Castro, sendo simultaneamente amigo e inimigo (2001:24). Na maioria dos casos, os homens evitam escolher seus cunhados reais, ngillan, para serem kon. Afirmam que é porque já estão obrigados a manter boas relações com eles e a serem hospitaleiros. Em outras palavras, com os afins "reais", a potencialidade implicada na relação kon/kayñe já está assegurada - eles se tornaram, desanimadoramente, consangüíneos. O relacionamento é fechado e a série de obrigações que ele implica já parece afetar a liberdade da pessoa.

A questão-chave mantém-se: por que "inimigos" e "amigos" são as mesmas pessoas? Apresento duas soluções possíveis: a primeira é simplesmente acrescentar o prefixo potencial a nossas traduções. Kon/kayñe seriam então amigos potenciais ou inimigos potenciais - a fascinação intrínseca que exercem sobre os homens mapuche residindo no fato de não estarem predeterminados ou obrigados a ser nem um nem outro. Uma segunda solução possível é que, em termos estruturais, não há diferença entre os dois conceitos. O ponto crucial reside no fato de a autonomia e o igualitarismo 
serem dois valores fundamentais da socialidade mapuche; amigo/inimigo sendo, portanto, o primeiro relacionamento a encerrar ambos os valores, já que se estabelece livremente e não contém elementos hierárquicos. ${ }^{18}$ Tenhamos essa idéia em mente quando prosseguirmos no exame de como o jogo do palin realça em si mesmo a oposição entre os jogadores individuais e seus kon/kayñe.

As duas equipes formam filas que se defrontam e se estendem ao longo de toda a parte central do campo de jogo. Cada jogador fica frente a frente com o adversário que lhe corresponde na outra equipe, e é com eleo kon/kayñe - que se dá a disputa direta. Os dois ficam lado a lado e, ocasionalmente, um empurra o outro tentando desequilibrá-lo e ganhar uma fração de segundo de vantagem para reagir à trajetória da bola. Quando ela está em jogo, os dois adversários avançam e recuam dentro do campo sem se separarem. O jogador da equipe que tem a posse de bola tentará se livrar do oponente que, por sua vez, fará de tudo para impedi-lo. Pode tentar segurá-lo pelo braço ou pelas pernas, ou chocar o bastão com o do adversário. Há poucas tentativas de passar a bola para outros jogadores - ela é, tanto quanto possível, simplesmente rebatida para a frente, em linha reta. Muito raramente um jogador tem contato com um adversário que não seja seu kon/ kayñe. O deslocamento progressivo da bola em direção a um gol ou ao outro resulta da soma das disputas individuais entre os kon/kayñe, e não de um esforço de equipe e, assim, a estrutura do jogo propriamente dito pode ser entendida como um meio de realçar a oposição do par konwen/kayñewen.

\section{Reciprocidade e hospitalidade}

Sustentei, em outro trabalho, que a troca recíproca é uma das formas fundamentais da socialidade entre os Mapuche (Course 2005; Kradolfer 2002). A reciprocidade é tanto o símbolo quanto o instrumento de certos tipos de relação. As pessoas são amigas porque praticam a reciprocidade e trocam em reciprocidade porque são amigas. Há, porém, diferenças sutis entre os tipos de práticas de reciprocidade existentes. Neste artigo, sustento que as duas formas ligeiramente diferentes de troca recíproca observadas no palin refletem por sua vez dois tipos diferentes de troca: a direta, entre oponentes, e as trocas generalizadas, que ocorrem entre dois lof, e entre o lof visitante e os koye, os "visitantes não-convidados".

Quando o palin entre os dois lof participantes termina, cada jogador do lof anfitrião convida seu adversário e seu núcleo familiar para irem até o lugar em que a mesa dele está posta. Os convidados são chamados a se 
sentar e cada um recebe um pedaço de carne ensopada, seguido de uma grande porção de carne assada e pão. O homem que convida seu adversário também lhe oferece uma caixa ou garrafa de vinho. As pessoas prestam muita atenção na quantidade exata de carne que receberam, e a generosidade ou avareza relativas dos diversos adversários costuma ser o principal assunto das conversas do dia seguinte. Podem-se ver as mulheres contando o número exato de pedaços de pão que receberam. Os homens com freqüência oferecem a seus adversários quantidades relativamente grandes de carne, mas cuidam para não ultrapassar aquilo que é dado pelo ñidol a seu par, o que seria considerado uma grosseria e um insulto à generosidade do ñidol. A troca que se dá entre os dois ñidol é ligeiramente diferente daquela entre os kon. O ñidol anfitrião oferece a seu oponente uma grande quantidade de carne, pelo menos metade de um porco, e vários jarros grandes de vinho. O ñidol visitante então corta sua carne e a oferece a quem quiser. $\mathrm{O}$ vinho também é repartido em garrafas de vidro e distribuído.

Todos sabem que a generosidade da oferta de um homem a seu oponente deve ser retribuída, o que ocorre quando o palin é "devolvido", em data posterior, pelo lof visitante. Idealmente, o ciclo recíproco envolve quatro partidas realizadas no período de um ano: o palin inicial, seguido pela primeira retribuição, e o segundo palin e a nova retribuição. Hoje em dia, no entanto, ele consiste, usualmente, em apenas uma partida e sua recíproca. Os informantes afirmam que isso se deve aos altos custos e à pobreza crescente. A retribuição de comida e vinho por ocasião da "devolução" do palin é de grande importância. Se uma pessoa receber do kon menos do que lhe deu anteriormente, sentir-se-á insultada e eventualmente começará a gritar impropérios, de pé. Se receber mais do que havia oferecido, o sentimento será de ligeira vergonha, e ela não se manifestará sobre o assunto. Não há, contudo, nenhum sentido ou elemento de competição nestas trocas. Um homem cuida de só oferecer aquilo que sabe que seu oponente terá condições de retribuir; quando isso não se dá, é geralmente em razão de algum engano ou mal-entendido, e não por manobra intencional. ${ }^{19}$ Algumas pessoas afirmam que a quantidade de carne trocada vem aumentando ao longo dos anos, e que, antes, oferecia-se aos adversários apenas chupilka, vinho misturado com trigo tostado. Parece, no entanto, que a troca de carne só fez diminuir durante o período de pobreza extrema, em meados do século XX.

É bastante comum a maioria das pessoas presentes em um palin não pertencer nem ao lof anfitrião nem ao visitante, mas sim a um dos muitos lof vizinhos. Estas pessoas são os koye, termo que pode ser frouxamente traduzido por "visitantes não-convidados". ${ }^{20}$ As pessoas do lof anfitrião e do visitante chegam na condição de famílias; já os koye são sempre homens. As 
poucas mulheres presentes e que não pertencem nem ao lof anfitrião nem ao visitante são aquelas casadas fora do grupo e ligadas ao lof anfitrião por laços patrilineares; elas não procuram obter hospitalidade, como o fazem os koye (homens). As relações de reciprocidade mantidas com determinado koye podem muito bem ser tão importantes quanto aquelas que a pessoa tem com o seu kon. No entanto, elas se dão de maneira diferente: se é a quantidade de comida oferecida que marca a relação com o kon, em relação aos koye o que conta é o fato de se convidá-los, ou não, para cear.

Os koye chegam ao longo do dia para assistir ao palin, participar de jogos de kayñetu, "palin de inimigo", e para koyekan, isto é, "receber a hospitalidade dos anfitriões" ou, como meus amigos geralmente dizem, "comer carne". O tratamento dos koye no palin é similar ao que se dá nos funerais. Ao chegarem, eles ficam de pé numa extremidade do campo de jogo e conversam entre si até que um dos anfitriões vá até eles e convideos individualmente para irem à sua mesa. São tratados exatamente como o oponente, kon, e recebem carne e vinho, embora, ao contrário dos oponentes, não dêem atenção especial às quantidades exatas recebidas, já que a retribuição será geral, e não direta como no caso do kon. Pode haver vários koye e vários kon em uma mesa. Quando a pessoa termina de beber seu vinho e de comer, deixa a mesa para dar lugar a outra e, quase imediatamente, é chamada para a mesa de algum outro amigo do lof anfitrião. É preciso notar que, a partir do momento em que o kon termina de comer e beber à mesa de seu parceiro, passa a ser como o koye, isto é, a hospitalidade que recebe daí em diante será retribuída indiretamente, e não de forma direta. À medida que koye e kon vão de mesa em mesa, os sacos plásticos em que levam seus nacos de carne vão aumentando, e sua sobriedade, diminuindo. Observamos que a forma de troca entre os kon é diferente da que ocorre entre os membros do lof anfitrião e os koye, e entre os membros do lof anfitrião e os do lof visitante que não são kon. Se a troca entre estes últimos é exata, direta e obrigatória, a troca entre os koye e os visitantes similares a koye (membros do lof visitante) é generalizada, indireta e espontânea. Todavia, ambas as formas têm em comum os traços essenciais da socialidade de trocas mapuche: igualdade de status e autonomia de participação.

No fim da tarde, quando o palin terminou, e a maioria das pessoas já comeu, alguns visitantes não-convidados, koye, começam a tentar organizar o kayñetu - um palin em seu estado menos elaborado, despido das obrigações da troca recíproca. É a ocasião que mais se aproxima da pura oposição, donde seu nome, derivado do substantivo kayñe, "inimigo". O ñidol, no kayñetu, pode ser qualquer um que se proponha a assumir a responsabilidade de formar uma equipe - sempre constituída por nove jogadores. A seleção 
dos jogadores, na formação das equipes do palin comum, se dá segundo as alianças do lof; já numa equipe do kayñetu entra qualquer um que quiser jogar. No entanto, a tendência, efetivamente, é que as equipes sejam formadas por pessoas da mesma área geográfica, ainda que de diferentes lof; seria também muito incomum que dois homens do mesmo lof jogassem como adversários em um kayñetu.

No momento em que o kayñetu é realizado, a maioria dos participantes já está muito embriagada. É, em parte, por esse motivo que este jogo é mais rápido e mais agressivo do que o palin normal. Também nele, cada jogador emparelha com um adversário - mas no palin comum, o par pode ser designado konwen ou kayñewen, ao passo que no kayñetu ele é sempre kayñewen, "inimigos mútuos". O kayñetu é quase sempre jogado em apenas "uma partida", kiñe kuden, o que garante que ele não se prolongue demais - apesar de que não raro as pessoas o abandonem antes mesmo de chegar esse estágio. Os kayñewen com freqüência fazem pequenas apostas de caixas de vinho ou garrafas de chicha. Segundo a etiqueta dos Mapuche para consumir vinho, o prêmio deve ser bebido conjuntamente pelos dois oponentes, mas entre eles não se dá nenhuma troca recíproca. Disputam-se várias partidas de kayñetu, até que não haja mais luz suficiente para continuar. Em certo sentido, ele é o passo final em direção ao interior, em nossos círculos concêntricos de alteridade. ${ }^{21}$ Ele difere do palin comum por haver agora ainda menos relação de identidade no interior de cada lado.

\section{Conclusão}

Neste artigo, sugeri que o palin constitui a institucionalização de um vínculo com outros, sob formas distintas e em vários níveis. Recorrendo ao conceito de afinidade potencial, esforcei-me por mostrar que a importância dos diferentes níveis e formas de oposição emerge em distintos contextos sociais e históricos. Assim, durante a época do conflito com os espanhóis e, contemporaneamente, por ocasião das manifestações políticas contra o Estado chileno, é o palin que representa a oposição étnica dos Mapuche contra os winka. Nesta oposição, o grupo, como um todo, representa um interior de identidade contra um exterior de diferença não-mapuche. Em outro nível, no entanto, a oposição-chave pode ser aquela entre as duas equipes que disputam o palin; ainda em outro nível, a oposição entre uma pessoa individualizada e seu adversário pode ter significado primordial. A questão é que o palin institucionaliza, encerra dentro de si e oferece essa pluralidade de significados; ele é atravessado pela fronteira entre igualdade 
e diferença, entre interior e exterior, entre nós e eles, entre si e outrem, entre self e outro. Foi esta pluralidade encerrada dentro da afinidade potencial que lhe permitiu preservar sua fundamental importância, apesar das inúmeras mudanças radicais que se deram no tecido mesmo da vida mapuche.

A discussão aqui empreendida limitou-se a um esporte praticado por um povo ameríndio periférico em relação ao Estado-nação dentro do qual se encontra e também em relação às correntes principais da etnografia sulamericana, voltada sobretudo para os Andes e a Amazônia. Espero, porém, que a etnografia apresentada venha reforçar uma série de oposições assimétricas apontadas, explícita ou implicitamente, em etnografias de outras partes das Américas. A diversidade dos povos nativos americanos é imensa, não importa o referencial que se escolha para tratá-la: cultural, lingüístico, social, histórico ou outro. Contudo, sob esta heterogeneidade caleidoscópica parece haver certos elementos comuns, certos temas e interesses recorrentes nos modos pelos quais os povos ameríndios representam, imaginam e organizam seus mundos sociais. Destes aspectos em comum, um dos mais difundidos, aparentemente, é o papel constitutivo de uma relação particular de oposição assimétrica (Lévi-Strauss 1996; Ewart 2003). Demonstrou-se que tal relação é de fundamental importância nas esferas do mito, do parentesco, da organização social e da pessoa. Concentrando minha atenção na importância das oposições assimétricas dentro do palin, esporte mapuche, espero ter demonstrado a relevância desta abordagem dos esportes ameríndios e, por conseguinte, e de modo mais geral, a relevância destes últimos para a socialidade ameríndia.

Recebido em 23 de janeiro de 2007

Aprovado em 08 de janeiro de 2008

Traduzido por Amir Geiger

Magnus Course é lecturer de antropologia social na Universidade de Edimburgo. E-mail: < M.E.Course@lse.ac.uk> Web: <www.san.ed.ac.uk> 


\section{Notas}

* Este artigo baseia-se em um trabalho de campo de 23 meses, conduzido entre 2001 e 2003, nos distritos vizinhos de Piedra Alta e Isla Huapi, em volta do lago Budi, no Chile. O trabalho de campo foi financiado pelo Economic and Social Research Council, pelo Central Research Fund da Universidade de Londres e pelo Prêmio Sutasoma, administrado pelo Royal Anthropological Institute. O texto foi escrito no período de bolsa de pós-doutorado da British Academy. Agradeço o apoio de todas estas instituições. Versões anteriores foram apresentadas no Seminário de Tese na London School of Economics, e no Seminário de Antropologia da América Latina, da LSE. Sou especialmente grato a Rita Astuti, Philippe Descola, Matthew Engelke, Peter Gow, Olivia Harris, Maya Mayblin e Michael Scott por seus comentários às versões prévias. Minha dívida maior é com os muitos palife na área de Piedra Alta e Huapi que dividiram comigo sua compreensão do palin.

${ }^{1} \mathrm{O}$ termo identidade é empregado aqui no sentido que Ricoeur lhe dá, de idemidentidade: uma relação de igualdade [de algo] consigo mesmo.

${ }^{2}$ Para um relato das lutas políticas mapuche ao longo de todo o século XX, ver Mallon 2005 e Foerster \& Montecino 1988.

${ }^{3}$ Há controvérsias a respeito dos vários censos da população mapuche no Chilequestão integralmente discutida em Saavedra 2002.

${ }^{4}$ Em outras áreas mapuche, o termo empregado é küpalme.

${ }^{5}$ Um lof é uma unidade social que se torna proeminente em especial nos funerais e nos jogos palin. É muito heterogêneo: em alguns casos, é definido principalmente pelo parentesco e, em outros, pelo território. Ver Course 2005 para uma discussão detalhada da composição dos lof.

${ }^{6}$ Embora o sistema das reservas tenha sido abolido muitos anos antes, as pessoas ainda falavam das suas comunidades como reducciones, "reservas".

${ }^{7}$ Para uma descrição mais completa das relações sociais mapuche, ver Course 2005.

${ }^{8}$ Para um relato das práticas funerárias mapuche, ver Course 2007.

${ }^{9}$ Àqueles temporariamente incapazes de se envolver na socialidade da amizade como um recém-nascido, ou alguém que esteja embriagado - nega-se o status de verdadeiras pessoas, sendo, portanto, designados como chenglay, "não-pessoas".

${ }^{10}$ A palavra wüño provém da raiz verbal wüño, que significa "retornar, devolver" e designa a curva na extremidade do bastão. A palavra tem sido traduzida impreci- 
samente para o espanhol como chueca, "encurvada", sendo essa a palavra espanhola utilizada para designar o jogo como um todo.

${ }^{11}$ A etimologia de winka é obscura; alguns sugerem we inka, outros propõem o verbo winkan. Embora a palavra tenha claras conotações pejorativas, emprego-a aqui por ser o único termo com que os Mapuche descrevem essa distinção étnica.

${ }^{12}$ Ironicamente, os líderes mapuche dos séculos XVI e XVII, como Lautaro, Caupolican e Galvarino, são freqüentemente representados como os primeiros heróis da luta pela independência do Chile.

${ }^{13}$ Isso lembra a análise, por Lévi-Strauss, dos "Gahuku-gama, da Nova-Guiné, que aprenderam o futebol, mas que jogam, vários dias seguidos, tantas partidas quantas se tornem necessárias para que se equilibrem exatamente as perdidas e as ganhas por cada equipe [...] o que é tratar o jogo como um rito" (1976:52).

${ }^{14}$ Em outras áreas mapuche, os xamãs (machi) também são necessários para se realizar um purrun palin. Para uma elaboração mais extensa sobre o papel social dos xamãs mapuche, ver Bacigalupo 2007.

${ }^{15}$ É interessante notar que, neste contexto, "os brancos" são representados como a fonte da divisão na sociedade mapuche.

${ }^{16} \mathrm{Na}$ maioria dos outras áreas da Araucania, os rewe são construídos com foye (Drimys winteri).

${ }^{17}$ Ao que parece, costumava haver um gênero de palin ül, "canções do palin", mas hoje em dia elas são raramente entoadas.

${ }^{18}$ Relações de hostilidade na sociedade mapuche raramente tinham a ver com a sujeição da vontade dos outros, e sim com o simples ato de apossar-se de sua propriedade ou de matá-los.

${ }^{19}$ É interessante notar que, uma vez mais, os participantes, dentro do palin, tentam alcançar um certo grau de equilíbrio e simetria no interior de uma relação mais ampla e abrangente de assimetria.

20 Os koye são uma característica de todos os acontecimentos sociais dos Mapuche: funerais, palin e os rituais de fertilidade, ngillatun.

${ }^{21}$ Viveiros de Castro sugeriu que a seqüência de oposições pode continuar para além do nível da pessoa, daí a pessoa "dividual" ameríndia poder separar-se em um corpo "interior" e uma alma "exterior" (2001). À luz dessa possibilidade, é interessante notar que as comunidades mapuche no Chile e na Argentina consideram o palin como governado por Kalfülikan, que é a divindade do palin e o palife celestial. Ele tem a forma de um esqueleto, sem "alma", alwe, nem "carne", ilo (Ñanculef 1993:5). 


\section{Referências bibliográficas}

BACIGALUPO, Ana Mariella. 2007. Shamans of the foye tree: gender, power, and healing among the chilean Mapuche. Austin: University of Texas Press.

COÑA, Pascual. 1984 [1930]. Testimonio de un cacique mapuche. Santiago: Pehuen. (Publicado originalmente sob o nome de Wilhelm de Moesbach.)

COOPER, John. M. 1946. "The Araucanians". In: J. Steward (org.), Handbook of South American indians. vol. 2 Washington D.C.: Smithsonian Institution. pp. 687-760.

CÓRdobA Y FIGUeroA，Pedro. 1862 [1740]. Historia de Chile. Santiago: Colección de Historiadores y Documentos Relativos a la Historia Nacional.

COURSE, Magnus. 2005. Mapuche person, Mapuche people: individual and society in indigenous Southern Chile. Ph.D. Thesis, University of London.

- 2007. "Death, biography, and the mapuche person". Ethnos, 72(1):77101.

EWART, Elizabeth. 2003. "Lines and circles: images of time in a Panará village". Journal of the Royal Anthropological Institute, 9:261-280.

FARON, Louis C. 1956. "Araucanian patri-organization and the omaha system". American Anthropologist, 58:435-456.

- 1961a. Mapuche social structure: institutional reintegration in a patrilineal society of central Chile. Urbana: University of Illinois Press.

. 1961b. "The Dakota-Omaha continuum in mapuche society". Journal of the Royal Anthropological Institute, 91: 11-22.
FOERSTER, Rolf; MONTECINO, Sonia. 1988. Organizaciones, líderes y contiendas mapuches: 1900-1970. Santiago: CEM.

GUEVARA, Tomás. 1908. Psicología del pueblo araucano. Santiago: Imprenta Cervantes.

- 1925. Historia de Chile: Chile prehispano. Santiago: Balcells \& Co.

KRADOLFER, Sabine. 2002. "Economic relations, cooperation, and reciprocity in Mapuche communities". In: C. Briones; J. Lanata (orgs.), Contemporary perspectives on the native peoples of Pampa, Patagonia, and Tierra del Fuego: living on the edge. Westport: Bergin \& Garvey. pp. 79-90.

LATCHAM, Ricardo. 1924. La organización social y las creencias religiosas de los antiguos araucanos. Santiago: Imprenta Cervantes.

LÉVI-STRAUSS, Claude. 1963. Structural anthropology. New York: Basic Books. - 1966. The savage mind. London: Weidenfeld \& Nicholson. . 1976. O pensamento selvagem. São Paulo: Cia. Editora Nacional. - 1996. The story of lynx. Chicago: University of Chicago Press.

MALLON, Florencia. 2005. Courage tastes of blood: the mapuche community of Nicolás Ailío and the chilean state, 1906-2001. Durham: Duke University Press.

MANQUILEF, Manuel. 1914. Comentarios del pueblo araucano II: la jimnasia nacional (juegos, ejercicios y bailes). Santiago: Imprenta Barcelona.

ÑANCULEF, Juan. 1993. El palin: deporte integral mapuche. Temuco: Comunicaciones Xeg-Xeg. 
ROSALES, Diego de. 1989 [1674]. Historia general del reino de Chile. Santiago: Editorial Andres Bello.

SAAVEDRA, Alejandro. 2002. Los mapuche en la sociedad chilena actual. Santiago: Lom.

STRATHERN, Marilyn. 1992. "Parts and wholes: refiguring relationships in a post-plural world". In: A. Kuper (org.), Conceptualizing society. London: Routledge. pp. 75-106.

STUCHLIK, Milan. 1976. Life on a half share: mechanisms of social recruitment among the Mapuche of Southern Chile. New York: St. Martin's Press.

TITIEV, Mischa. 1951. Araucanian culture in transition. Ann Arbor: University of Michigan Press.

VIVEIROS DE CASTRO, Eduardo. 1992. From the enemy's point of view: humanity and divinity in an Amazonian society. Chicago: University of Chicago Press.

- 1998. "Cosmological deixis and Amerindian perspectivism". Journal of the Royal Anthropological Institute, 4:469-488.

- 2001. "Gut feelings about Amazonia: potential affinity and the construction of sociality". In: L. Rival; N. Whitehead (orgs.), Beyond the visible and the material: the amerindianization of society in the work of Peter Riviere. Oxford: Oxford University Press. pp. 19-43. - 2002. A inconstância da alma selvagem e outros ensaios de antropologia. São Paulo: Cosac \& Naify. 
Resumo

Combinando dados históricos e etnográficos, este artigo explora a importância dos vários níveis de oposição dentro do esporte do palin e as práticas sociais que o cercam, nas comunidades indígenas mapuche, no sul do Chile. Empregando o conceito de afinidade potencial, procuro analisar de que modo a oposição entre identidade e diferença toma formas distintas - como a guerra, o ritual ou o intercâmbio - em níveis distintos de análise, tais como os grupos étnicos, o grupo local e a pessoa. Essa multiplicidade de oposições está relacionada com a variedade dos contextos históricos nos quais o palin tem sido importante. Concentrando a atenção na relevância das relações de alteridade dentro do palin, este artigo procura expandir para o domínio do esporte indígena a aplicação da abordagem antropológica da socialidade ameríndia, abordagem esta geralmente restrita ao parentesco e à mitologia.

Palavras-chave Mapuche, Esporte, Alteridade, Estrutura, Chile
Abstract

Combining historical and ethnographical data, this paper explores the importance of various levels of opposition in the sport of palin and the social practices that surround it in the Mapuche communities of southern Chile. Using the concept of potential affinity, I seek to analyse the way in which the opposition between identity and difference takes distinct forms - such as those of warfare, ritual and exchangeat different levels of analysis, such as that of the ethnic group, the local group and the person. This multiplicity of oppositions is related to the variety of historical contexts in which palin has been important. Focusing on the relevance of relations of alterity in palin, the article looks to apply to the domain of Indigenous sport the anthropological approach to Amerindian sociality, which has generally been restricted to kinship and myth.

Key words Mapuche, Sport, Alterity, Structure, Chile 